\title{
Educational Studies
}

\section{Pedagogical content knowledge of French as a foreign language: differences between pre-service and in-service teachers}

\section{Marie Evens, Kelly Tielemans, Jan Elen \& Fien Depaepe}

To cite this article: Marie Evens, Kelly Tielemans, Jan Elen \& Fien Depaepe (2018): Pedagogical content knowledge of French as a foreign language: differences between pre-service and in-service teachers, Educational Studies, DOI: 10.1080/03055698.2018.1446339

To link to this article: https://doi.org/10.1080/03055698.2018.1446339

曲 Published online: 08 Mar 2018.

Submit your article to this journal $\pi$

Q View related articles $\sqsubset$

View Crossmark data $₫$ 


\title{
Pedagogical content knowledge of French as a foreign language: differences between pre-service and in-service teachers
}

\author{
Marie Evens ${ }^{\mathrm{a}}$, Kelly Tielemans ${ }^{\mathrm{b}}$, Jan Elen ${ }^{\mathrm{a}}$ and Fien Depaepe
}

${ }^{a}$ Centre for Instructional Psychology and Technology, KU Leuven, Leuven, Belgium; ${ }^{b}$ Centre for Educational Effectiveness and Evaluation, KU Leuven, Leuven, Belgium; ITEC-imec, KU Leuven campus Kulak, Kortrijk, Belgium

\begin{abstract}
Pedagogical content knowledge (PCK) is an important predictor of educational quality. PCK develops from various sources, such as teaching experience. Studies investigating the effects of teaching experience on PCK development mainly focus on the question whether experienced teachers differ from novices in the amount of PCK. In a mixed methods study, we study both quantitative and qualitative differences between pre-service and in-service teachers' PCK. Total scores on a paper-and-pencil instrument are used as a measure of French PCK. To analyse the participants' PCK in a qualitative way, answers are coded in four categories and the prevalence of answers in each category is compared between groups. Furthermore, the nature of answers is studied. No differences on our quantitative PCK measure are observed. The qualitative analysis shows that inservice teachers have more difficulties with conceptual knowledge, while showing more practical knowledge of students' understanding than pre-service teachers.
\end{abstract}

\section{ARTICLE HISTORY}

Received 21 February 2017

Accepted 28 December 2017

\section{KEYWORDS}

Teacher professional knowledge; pedagogical content knowledge; foreign language teaching; teaching experience; teacher education

\section{Introduction}

\subsection{Conceptualisation of pedagogical content knowledge}

There is a shared understanding that teachers are key professionals in schools, and have a very important influence on instructional quality and student outcomes (Cochran-Smith and Zeichner 2005; Hattie 2012; Schleicher 2016). A variety of teacher characteristics affects instructional quality (Baumert and Kunter 2013), one of which is teachers' professional knowledge (Connelly, Clandinin, and He 1997). Research on teachers' professional knowledge is highly inspired by the work of Shulman $(1986,1987)$.

Shulman (1987) introduced the construct "pedagogical content knowledge" (PCK) as the most important category of teachers'knowledge base. He defined PCK as"that special amalgam of content and pedagogy that is uniquely the province of teachers, their own special form of professional understanding" (Shulman 1987, 8). In Shulman's (1986, 1987) 
conceptualisation, PCK entails two components: (1) the most commonly taught topics in a specific domain and their most useful representations, and (2) an understanding of what makes the learning of particular topics within a domain easy or difficult for students. Since Shulman's introduction of PCK, the construct has pervaded educational research, leading to several adaptations of his conceptualisation. Two very influential conceptualisations are the ones by Grossman (1990), and Magnusson, Krajcik, and Borko (1999). Grossman claimed that PCK contains four components, adding knowledge of curriculum and knowledge of purposes for teaching to Shulman's initial conceptualisation. Magnusson, Krajcik, and Borko (1999) expanded Shulman's model with three components, that is, teaching orientations, knowledge of curriculum, and knowledge of assessment.

Across studies, two fundamentally different perspectives on PCK can be distinguished: a situated and a cognitive perspective (Depaepe, Verschaffel, and Kelchtermans 2013; Kaiser et al. 2017). The situated perspective considers PCK as dynamic knowledge that only becomes meaningful in the context of the classroom. Studies approaching PCK from this perspective are mainly small scale, aiming to capture knowledge in action. Commonly used instruments are interviews and classroom observations. By contrast, the cognitive perspective adheres to a more static point of view on PCK. Research approaching PCK from this perspective mainly includes large-scale studies, using quantitative instruments to capture theoretical, declarative knowledge in a generalisable way (Depaepe, Verschaffel, and Kelchtermans 2013; Kaiser et al. 2017). Both perspectives complement each other and contribute to a thorough and nuanced investigation of PCK. The present study is guided by a cognitive perspective on teachers' professional knowledge.

From a cognitive perspective, the importance of PCK has been confirmed by empirical research, showing a significantly positive relationship between teachers' PCK and student outcomes. Baumert et al. (2010) found positive effects of teachers' subject matter knowledge $(\beta=.30)$, and especially their PCK $(\beta=.42)$, on instructional quality and on students' learning gains in mathematics. Kunter et al. (2013) confirmed these results in a study combining PCK $(\beta=.38)$, professional beliefs, work-related motivation and self-regulation in one comprehensive model. In the science domain, Mahler, Großschedl, and Harms (2017) found a positive impact of biology teachers'PCK on student achievement $(\beta=.36)$. Förtsch et al. (2016) found an indirect positive effect of biology teachers' PCK $(\beta=.32)$ on student achievement, mediated through the extent to which teachers fostered students' cognitive activation. The same indirect effect was found by Keller, Neumann, and Fischer (2017) in the physics domain $(\beta=.44)$.

\subsection{Development of PCK}

Teachers draw their professional knowledge from various sources (Evens, Elen, and Depaepe 2015; Grossman 1990; Kind 2009). According to Friedrichsen et al. (2009) PCK develops from the following sources: prior learning experiences, teacher education (TE), and teaching experiences. Firstly, prior learning experiences as a student have an influence on teachers' current teaching models (i.e. "apprenticeship of observation") (Lortie 1975). Empirical studies showed that teachers consider their memories of past education as an important source of professional knowledge (Eick and Reed 2002; Haston and Leon-Guerrero 2008). Unfortunately, these memories may also limit teachers to simplified views of teaching, only relying on familiar curricular materials and approaches (Haston and Leon-Guerrero 2008; Labaree 2000). Secondly, courses in TE have an impact on teachers' PCK development. Research has shown 
that more courses on PCK lead to more PCK development (i.e. the number of learning opportunities) (Evens, Elen, and Depaepe 2017), and that the inclusion of specific topics in TE (i.e. the content of learning opportunities) also positively impacts PCK (Blömeke et al. 2012; Qian and Youngs 2016). Thirdly, experience in teaching is recognised as a possible source for teachers' professional knowledge (Grossman 1990). Most authors agree that there is no direct impact of teaching experience on PCK, but rather an impact that is mediated by reflection (Schön 1983). In other words, it is often concluded that experience does not cover the same meaning as expertise (Hattie 2012). According to Ericsson, Krampe, and Tesch-Römer (1993) the difference between expertise and experience can be explained by the notion of "deliberate practice", which are those activities that are highly relevant to performance improvement, require significant effort, and are motivated by a goal of improvement (Ericsson, Krampe, and Tesch-Römer 1993). In the context of teaching, deliberate practice is provoked during planning and evaluation activities that are performed with continued frequency, that are carried out when it is not absolutely necessary to do so, and that are guided by goals of self-improvement rather than by goals of student improvement (Dunn and Shriner 1999). A very important role in this process is played by feedback from coaches and mentors. The conditions of deliberate practice are not always obvious in everyday school life (Krauss, Baumert, and Blum 2008a), which implies that not all experienced teachers are experts.

The impact of teaching experience on PCK development is studied from a cognitive and situated perspective, leading to different results. Studies approaching PCK from a cognitive perspective mostly found no or only small effects of teaching experience on PCK, as measured by total scores on quantitative instruments. In a study with 195 in-service mathematics teachers, Brunner et al. (2006) found no significant impact of teaching experience on teachers' PCK ( $r=-.14, p<.05)$. In a large-scale cross-sectional study by Kleickmann et al. (2013), four groups with different teaching experience (pre-service teachers in the beginning and at the end of their university studies, teachers at the end of their induction phase, and in-service teachers with an average of 21 years of teaching experience) were compared in terms of PCK $(N=980)$. The study showed that the induction phase and the in-service phase did not foster the development of PCK as strongly as pre-service TE.

Studies investigating the impact of teaching experience on PCK from a situated perspective provide a more nuanced picture. Lee et al. (2007) followed 24 beginning science teachers throughout their first year as a teacher and compared them with a group of teachers with more than 10 years of experience. The proficiency of participants' PCK (their knowledge of student learning and instructional strategies) expressed during interviews and classroom observations was judged using a rubric based on three proficiency levels (limited, basic, proficient). All beginning teachers had basic or limited levels of PCK. An improvement in knowledge of student learning was found throughout the first year, while participants' knowledge of instructional strategies did not improve. On the other hand, the more experienced group had proficient levels of PCK. These findings suggest that PCK develops through teaching experience. Friedrichsen et al. (2009) compared two groups of two students entering an alternative biology TE programme (i.e. a programme that is shorter in duration than traditional programmes, mainly to address teacher shortages). The groups differed regarding teaching experience (i.e. no experience versus two years of experience). PCK was elicited by means of a lesson preparation assignment and a follow-up interview. Only small differences regarding the amount of topic-specific PCK on the topic of heritable variation between the groups were found. In a broader analysis, also including discipline-specific PCK, some 
differences between groups were found. Participants with teaching experience showed slightly more discipline-specific PCK, and provided more elaborate reflections, integrating multiple knowledge bases (such as general pedagogical knowledge) when explaining their thinking. Clermont, Borko, and Krajcik (1994) compared experienced and novice teachers in a study on the topic of chemical demonstrations. They found that experienced teachers knew more instructional strategies than novice teachers that experienced teachers were able to use particular demonstrations more flexibly, and that experienced teachers could adapt their demonstrations to student learning in a more effective way. Similarly, Park and Oliver (2008) conducted a multiple case study with three experienced chemistry teachers. Participants' PCK was mapped by means of several classroom observations, interviews, and document analyses. These authors concluded that PCK developed over time. Opportunities for reflection-in-action and reflection-on-action (Schön 1983), that teachers encountered when they gained more experience, positively impacted the integration of PCK components.

There are at least two possible, complementary explanations for the different findings of cognitive and situated studies. Firstly, both perspectives measure different types of knowledge. Cognitive studies focus on theoretical, declarative knowledge (Depaepe, Verschaffel, and Kelchtermans 2013; Kaiser et al. 2017). Teachers' professional knowledge is considered as public knowledge (Gess-Newsome 2015). Situated PCK research maps a different kind of knowledge, that is, private knowledge, held by individuals, and generated in close relation to classroom practice (Gess-Newsome 2015). PCK is considered as a kind of "craft knowledge", which is the knowledge representing teachers' accumulated wisdom regarding their teaching practice, and guiding their behaviour during classroom practice (van Driel, Verloop, and de Vos 1998). Craft knowledge is not opposite to theoretical knowledge, but is instead based on both teachers' prior education and their practical experiences (van Driel, Verloop, and de Vos 1998; Verloop, Van Driel, and Meijer 2001). Craft knowledge is however not always in line with theoretical conceptions of teaching and learning (Day 2005; van Driel, Verloop, and de Vos 1998). The absence of effects of teaching experience on PCK in cognitive studies might be explained by the observation that the learning content in TE is more closely related to the declarative, theoretical knowledge assessed in cognitive studies than to teachers' practical, craft knowledge.

Secondly, cognitive studies only used the total scores on quantitative instruments as a measure of teachers' PCK, and as such provided an answer on the question how much PCK their participants had. Situated studies focused mainly on descriptions of participants' PCK, and as such studied how much and what kind of PCK their participants had. Studies focusing on how much PCK participants have mainly found no or only small differences based on teaching experience (Brunner et al. 2006; Kleickmann et al. 2013). Studies also focusing on the question of what kind of PCK participants have revealed several kinds of differences between experienced teachers and novices. The study by Friedrichsen et al. (2009) illustrates this idea: no differences in the amount of PCK between experienced and inexperienced teachers were found, whereas regarding the kind of PCK different findings were observed. For instance, experienced teachers more often integrated general pedagogical knowledge in their reflections than inexperienced teachers. 


\subsection{Present study}

To better understand the discrepancies between findings generated in cognitive and situated studies, the present study uses mixed methods and not only investigates how much theoretical knowledge participants have by means of short open-answer items (in line with a cognitive perspective), but also studies the kind of knowledge of teachers by looking at the nature of answers in a more qualitative way (as inspired by a situated perspective).

The present study focuses on PCK in the domain of foreign languages, and more specifically on French, that is taught as a foreign language in upper primary education in Flanders, Belgium. As most of the above described studies are situated in the domains of mathematics and sciences, it is unclear whether teaching experience impacts PCK development in the same way in the foreign language domain. This disciplinary domain is distinct from the domains of mathematics and sciences in that content and medium of instruction are the same in language teaching. Foreign languages are usually taught in the target language. Language skills are taught to students (i.e. the content) while at the same time teachers actively use the target language (i.e. the medium) (Hlas and Hildebrandt 2010).

The present study is guided by the following research question: What are differences in the French PCK of pre-service and in-service teachers?

(a) What are quantitative differences in PCK?

(b) What are qualitative differences in PCK?

Given that we study PCK from a cognitive perspective, focusing on declarative knowledge, we expect to find no or only small quantitative differences between pre-service and in-service teachers. This expectation is based on previous cognitive research (Brunner et al. 2006; Kleickmann et al. 2013). Similar to previous studies that qualitatively studied teachers' PCK (Clermont, Borko, and Krajcik 1994; Friedrichsen et al. 2009; Park and Oliver 2008), we do expect to find qualitative differences between pre-service and in-service teachers.

\section{Methods}

\subsection{Participants and context}

The study took place in Flanders, Belgium. Flemish primary school teachers are generalists, teaching all courses that are part of primary education. French is an official language in Belgium. In Flanders it is taught as a foreign language, starting from the fifth grade of primary education.

The total sample consisted of 117 participants, of which 91 pre-service teachers and 26 in-service teachers. TE in Flanders comprises three years of study, leading to a Bachelor's degree (i.e. level 6 in the European qualification framework) (Bologna Working Group 2005). All pre-service participants were recruited from the third year of study of two TE institutes. In-service teachers were fifth and sixth grade teachers from 17 schools in Flanders. Teachers with a minimum of three years of experience were chosen with the aim to limit the sample to teachers who already got used to their position as a teacher. Background characteristics of both groups are displayed in Table 1. Of the pre-service teachers $91 \%$ were female, while $73 \%$ of the in-service teachers were female. This percentage is normal for the Flemish situation. 
Table 1. Overview of participants' background characteristics.

\begin{tabular}{llccccc}
\hline & & $N$ & Min & Max & M & SD \\
\hline Pre-service teachers & Age (years) & 84 & 20 & 44 & 21.32 & 3.25 \\
In-service teachers & Age (years) & 25 & 27 & 58 & 40.32 & 9.61 \\
& Teaching experience (years) & 26 & 4 & 38 & 17.92 & 9.87 \\
Total sample & Age (years) & 109 & 20 & 58 & 25.68 & 9.65 \\
\hline
\end{tabular}

\subsection{Instruments and analysis}

PCK was assessed by means of an open-answer paper-and-pencil instrument. Following a cognitive perspective on PCK, the instrument focused on declarative knowledge. The topic of the instrument is oral interaction (OI), one of the five skills that are included in the attainment targets of French in Flemish primary education (along with listening, speaking, reading, and writing). Ol is an alternation of production and reception. While one person is speaking, the other is forecasting the remainder of the message and preparing a reply. Speaking, on the other hand, is addressed when speakers give a monologue or take part in a dialogue in which they know beforehand what the other person will say (Council of Europe n.d.). Since communicative and task-based language teaching are gaining ground, $\mathrm{Ol}$ is receiving increasing attention in research, curricula, and TE (González Humanez and Arias 2009; Herazo Rivera 2010). Before starting with instrument development, we conducted interviews with 13 primary school teachers and 10 French teacher educators with the aim to ensure the instrument's content validity by exploring current approaches and needs with regard to OI. In general, primary school teachers indicated that they did not feel well prepared to teach $\mathrm{Ol}$, while Ol is becoming more important in manuals. Teacher educators confirmed this finding, and mentioned that the small amount of time provided for French in TE is mainly used for other topics.

The PCK instrument covers the following dimensions: knowledge of student understanding, knowledge of educational representations, knowledge of assessment, and knowledge of curriculum. The choice for these four domains was based on several considerations: theoretical PCK models (Grossman 1990; Magnusson, Krajcik, and Borko 1999; Shulman 1987), practical experiences of two teacher educators of French in primary education who assisted in developing the instruments, the Flemish primary education curriculum, and literature on French language teaching and learning in primary education (e.g. Kwakernaak 2009; Sercu, Vyncke, and Peters 2003; Theissen et al. 2015). The PCK instrument consists of eight openended short-answer questions, each having four sub-items. All items focus on one or more dimensions. The maximum score that can be obtained on the instrument is converted to 100 . An extensive discussion of the instrument is presented in Evens, Elen, and Depaepe (2017).

The data were processed in two rounds. In the first round (focusing on RQ1 about the total scores on PCK) all items were rated as correct or incorrect (scores 1 or 0 ), according to a correction key that was based on insights from the literature on French teaching and learning. This approach is similar to earlier studies that examined PCK from a cognitive perspective. An independent samples $t$-test was used to compare the total scores on the PCK instrument of the pre-service and in-service teachers. All the assumptions for independent samples $t$-tests were met.

In the second round, qualitative differences between groups were studied (RQ2). As the correct answers were already analysed in the first round, we aimed to complement these 
quantitative findings with more qualitative analyses on the answers that were coded as incorrect. A scoring rubric was developed in a data-driven way. All tests were scanned to search for commonalities among participants. Two raters inspected the tests with the aim of finding the most common reasons why answers were rated as incorrect. Next, the two raters compared their findings. This process led to a scoring rubric consisting of four categories, each standing for a specific reason why answers were coded as incorrect in the first coding round. The categories are described in Table 2. The total number of answers in each category (non-alignment, partial alignment, redundant answer, no answer) was calculated for each participant. These totals were used as dependent variables in a MANOVA, with teaching experience (pre-service versus in-service teachers) as the independent variable. All the assumptions for MANOVA were met. Next, we had a closer look in a more qualitative way at the findings concerning the answer categories. In view of understanding the outcomes, we analysed the specific answers given in a data-driven way, guided by the principles of grounded theory (Strauss and Corbin 1998). More specifically, we carefully read all answers belonging to each particular category, with the aim to elicit patterns from the data (i.e. to find out what kind of answers were characteristic for each category, and whether or not answers within categories differed between pre-service and in-service teachers).

Interrater reliability of the instrument was tested by calculating Cohen's $\mathrm{K}$ for the ratings of PCK quantity (scores of 0 or 1 ) and for the ratings of PCK quality (the four answer categories, phase 1 of the analyses of PCK quality). All answers of $10 \%$ of the tests were coded in two rounds by two raters, leading to very good agreement on both the quantity $(\kappa=.90)$ and the quality of PCK $(\kappa=.89)$ (Altman 1999). Cronbach's $\alpha$ was calculated to measure internal consistency of the paper-and-pencil test. An $\alpha$ of .59 was found. When looking at the two groups separately, $\alpha$ was .60 for the pre-service teachers and .51 for the in-service teachers. As the usefulness of Cronbach's $\alpha$ as a measure is questionable because of very often underestimating the reliability of an instrument (Bendermacher 2010; Sijtsma 2009), also Guttman's $\lambda_{2}$ was calculated, which was .61 in total, .64 for the pre-service teachers only, and .56 for the in-service teachers only. This indicates almost sufficient internal consistency.

\subsection{Procedure}

Several TE institutes were contacted to participate in the study. Two institutes agreed with participation. In both institutes, all students of the third year were invited by their teacher educators to take part. Participation was voluntary. The participating students were collectively assessed on PCK (in their own TE institute). The data collection sessions were supervised by a researcher and a teacher educator.

Several schools (in different locations throughout Flanders) were contacted to invite fifth and sixth grade teachers to participate in the study. The participating teachers voluntarily agreed to participate. Data collection took place in the schools. In every school, one or two teachers completed the instrument at the same time, under the supervision of a researcher.

All participants signed informed consent documents stating the objectives of the study, and confirming that their participation was voluntary. 


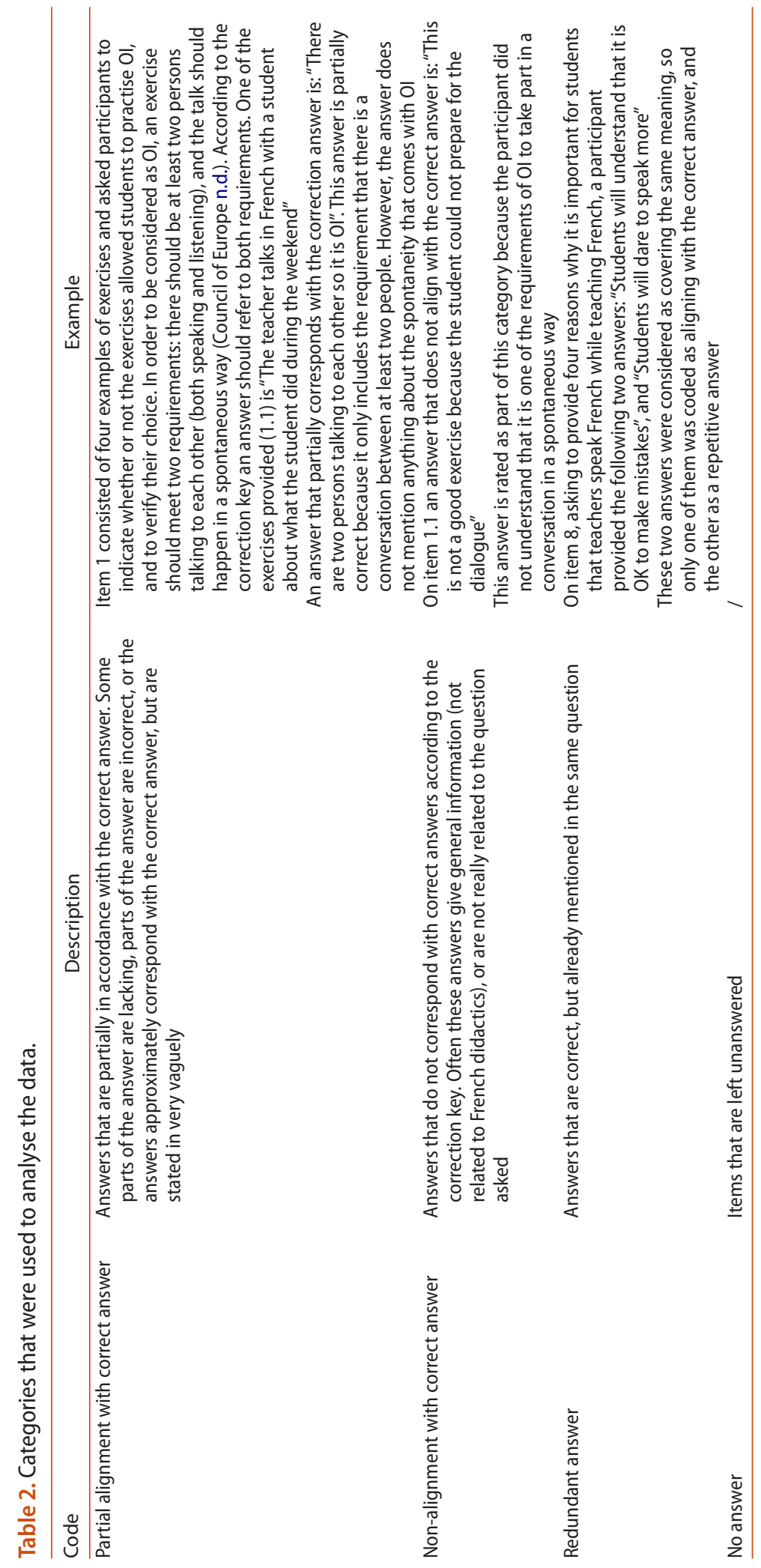




\section{Results}

\subsection{Quantitative differences in PCK between pre-service and in-service teachers}

Descriptive statistics concerning the total scores on the PCK instrument are displayed in Table 3. There are no differences in maximum scores between groups, and similar mean scores. However, the minimum score of the pre-service teachers is lower than the minimum score of the in-service teachers.

The mean scores of the pre-service teachers did not significantly differ from the in-service teachers, $t(114)=.45, p=.66,95 \% \mathrm{Cl}[-3.54,5.59], d=.11$.

\subsection{Qualitative differences in PCK between pre-service and in-service teachers}

The following qualitative differences between groups are found. In a MANOVA using Pillai's trace, a significant effect of group (pre-service versus in-service teachers) on participants' answer patterns was found, $V=.28, F(4,112)=10.98, p=<.001$. In the follow-up ANOVAs, no significant differences between pre-service $(M=.82, S D=.88)$ and in-service teachers $(M=.96, S D=1.11)$ were found with regard to repetitive answers, $F(1,115)=.44, p=.51$, $95 \% \mathrm{Cl}[-.55, .27], d=-0.14$. However, with respect to answers that did not align with the correct answers, in-service teachers $(M=10.88, S D=3.08)$ gave significantly more answers not aligning with the correct answer than pre-service teachers $(M=6.71, S D=3.24), F(1,115)$ $=34.30, p<.001,95 \% \mathrm{Cl}[-5.58,-2.76]$, with a large effect size, $d=1.32$. On the other hand, pre-service teachers $(M=3.62, S D=4.17)$ significantly more often provided no answer than in-service teachers $(M=.62, S D=1.17), F(1,115)=13.07, p<.001,95 \% \mathrm{Cl}[1.36,4.64]$ with a large effect size, $d=.98$. Pre-service teachers $(M=8.45, S D=2.56)$ also more often gave answers that partially agreed with the correct answer than in-service teachers $(M=7.12$, $S D=2.20), F(1,115)=5.85, p=.02,95 \% \mathrm{Cl}[.24,2.43]$, with a medium effect size, $d=.56$.

The answers of the participants were more closely studied (in a bottom-up approach) to understand the differences that were found in the (top-down) quantitative analyses. Firstly, many non-aligning answers of in-service teachers show that they do not know particular concepts. This finding mainly occurred on items focusing on the meaning of specific concepts (e.g. OI). Although there are some exceptions, most of the in-service teachers seemed to lack the conceptual knowledge about what these concepts comprise, and therefore, gave more answers not aligning with the correct answer. For instance, on item 1.2 (see Figure 1), a correct answer would indicate that this exercise is not an example of Ol because the conversation does not happen in a spontaneous way. The following quote of an in-service teacher illustrates that she does not know that the spontaneous element is indispensable when talking about OI. "If students talk to each other or to the teacher, it is an example of OI". (in-service teacher 1). Another example of the lack of particular conceptual knowledge of an in-service teacher is an answer to item 4.2 (see Figure 2). The validity of the evaluation suggested in this item is good because it assesses students' Ol ability. However, in-service

Table 3. Descriptive statistics concerning quantity of PCK.

\begin{tabular}{lcccc}
\hline & $M$ & $S D$ & Min & Max \\
\hline Pre-service teachers & 48.63 & 10.58 & 15 & 70 \\
In-service teachers & 47.60 & 8.68 & 34 & 70 \\
\hline
\end{tabular}




\section{Item 1}

Below you see four assignments. Indicate for each assignment whether or not the students are practicing oral interaction. Justify your choice. Your justification should show what you think oral interaction is.

Item 1.1. The teacher talks in French with a student about what the student did during the weekend.

Item 1.2. Two students recite a French dialogue by heart in front of the class.

Item 1.3. You are on a forest trip in Jodoigne and a student buys an ice cream in French.

Item 1.4. Assignment $B$ in the following exercise.

A) Combine the sentences. Write the number before the answer.

B) Cover the numbers on the right. One student says a sentence on the left, another student answers.

1. Il pleut!

2. Nous jouons au foot tout de suite?

3. Monsieur Perrin est le père d'Élise?

4. Vous avez des CD ici ?

5. Les enfants sont dans la classe?

6. C'est l'anniversaire de Sylvie!

7. Ton lapin s'appelle comment ?

8. Tu as une table?
. Non, il n'a pas d'enfants.

... Non, nous n'avons pas de ballon.

... Non, nous n'aimons pas la musique.

... Oh, il n'a pas de nom.

.. Oh, je n'ai pas de cadeau pour elle!

... Oh, je n'ai pas de parapluie!

... Oui, ils n'ont pas de vacances.

... Oui, mais je n'ai pas de chaise.

Figure 1. Item 1 of the PCK test instrument.

\section{Item 4}

A teacher has just addressed a basic dialogue and related vocabulary about clothes with his students. $\mathrm{He}$ is planning a test to evaluate the oral interaction of the students related to this theme. Judge the quality of the tests described below and justify your choice by indicating whether or not the tests have sufficient validity and authenticity.

Item 4.1. The students prepare in pairs a dialogue in a clothing store. Student 1 wants to buy clothes, student 2 plays the role of vendor. Afterwards the pairs go to the teacher to recite their dialogue.

Item 4.2. The students go to the teacher in pairs. The teacher gives them the assignment to each put on one piece of clothing out of a suitcase. The students engage in a conversation with each other; they ask questions about what they are wearing and they respond to each other's questions.

Item 4.3. One by one, the students take a piece of clothing out of a suitcase and put it on. They tell the class what they are wearing.

Item 4.4. The students go to the teacher one by one to talk in French with him about their favorite clothes.

Figure 2. Item 4 of the PCK test instrument.

teachers often gave answers showing that they did not understand what is meant by OI: "Students should have the opportunity to prepare this in advance, improvisation seems difficult to me". (in-service teacher 6). This teacher does not understand that improvisation is essential in OI. The same counts for the answer of in-service teacher 9 on item 4.3 
(see Figure 2). The test suggested in this item is clearly not a good way to evaluate $\mathrm{Ol}$ as there is no conversation between people, only a monologue. However, the teacher gave another argument: "A student with "stage fright" will definitely underachieve due to stress. It is a good exercise but not a good test". (in-service teacher 9). This teacher did not understand that, because of the lack of a conversation with other people, this example is also not suitable as an exercise for Ol, even if it is not meant to assess students.

Secondly, in-service teachers referred more to practical experiences than pre-service teachers. These often differed from the theoretical knowledge that was expected from a correct answer. For instance, on item 4.2 (see Figure 2) the following answer was given: "In itself it is very nice, but without preparation it is practically infeasible in a mainly Dutch speaking school". (in-service teacher 6). This teacher based her decision on practical feasibility rather than on whether or not the suggested test is valid and/or authentic. Furthermore, on item 4.3 (see Figure 2) one teacher answered: "This should be possible for the students because it does not yet include a dialogue. This is a good exercise to repeat vocabulary". (in-service teacher 7). This answer is not in line with the question asked but it does show that the teachers' practical experience with students allowed her to understand whether or not a particular exercise fits the students' level. The same counts for the following answer on the same item: "Maybe they are too nervous so they cannot think well". (in-service teacher 24). This answer shows that the teacher knows the effect of this kind of tests on students, but is no correct answer on the question. A typical answer of a pre-service teacher on this item focuses more on the theoretical knowledge targeted by the item: "There is no response of the other students so there is no interaction". (pre-service teacher 3 ).

Thirdly, pre-service teachers more often left items unanswered than in-service teachers. The number of students that provided no answer was the highest on item 7 on students' misconceptions. In-service teachers, by contrast, scored very well on this item. Besides leaving the question unanswered, pre-service teachers also gave more non-aligning answers on this item. An example of the latter is this answer on item 7.2 (see Figure 3): "This is incorrect, "grand" has to be in between "un" and "garçon"'.' (pre-service teacher 49). Answers like this one only focus on the detection of the mistake, but not on the reasoning of the student that made the mistake. In-service teachers mostly gave more thorough analyses of students' thinking, such as "Usually adjectives are positioned behind nouns, this student applied this rule to an exception". (in-service teacher 3 ).

Finally, pre-service teachers gave more partially aligning answers than in-service teachers. This does not concern specific items, but the entire test. For instance, the following answer

\section{Item 7}

Below you see four French sentences said by students, each including a mistake. Indicate for each sentence why the student most probably made the mistake. The mistakes are underlined.

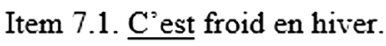

Item 7.2. Il est un garçon grand.

Item 7.3. Les enfants aimer le chocolat.

Item 7.4. Il va toujours dormir devant dix heures.

Figure 3. Item 7 of the PCK test instrument. 
was given on item 7.4 (see Figure 3): "This is how you say it in Dutch". (pre-service teacher 18). This answer was coded as partially correct because there is a link with the Dutch language in the answer, but the answer is not concrete enough. It does not mention that there are multiple words in French having the same translation as one word in Dutch. Furthermore, on item 8 (see Figure 4) a pre-service teacher gave the following answer: "The students hear more of the French language". (pre-service teacher 6). This answer was coded as partially correct because it does not explain why it is beneficial for students to hear more of a foreign language.

\section{Discussion and conclusions}

The present study compared the French PCK of pre-service and in-service teachers. Firstly, the study focused on the quantitative differences in PCK between groups. This question was studied by means of comparing total scores between groups on a PCK test instrument. Secondly, the qualitative differences were investigated by comparing the average number of answers in the following categories: non-alignment with the correct answer, partial alignment with the correct answer, redundant answer, no answer. These differences were further qualitatively analysed to unravel patterns of differences between pre-service and in-service teachers.

Concerning the quantitative differences, the groups did not significantly differ from each other. This finding is in accordance with previous studies (Brunner et al. 2006; Kleickmann et al. 2013). The present study approached PCK from a cognitive perspective, which implies that mainly declarative knowledge was assessed. Teaching experience did not seem to contribute to this kind of knowledge. The finding that experienced teachers did not outperform pre-service teachers confirms the idea that experience is not the same as expertise (Hattie 2012; Schön 1983). Mere experience does not seem to be sufficient for knowledge development, more possibilities for deliberate practice could be a way to improve teachers' expertise (Ericsson, Krampe, and Tesch-Römer 1993). The lack of feedback from coaches in most primary schools might also be a reason for the finding that in-service teachers did not perform better on the PCK test (Krauss, Baumert, and Blum 2008a). Furthermore, the lack of an effect of teaching experience might be explained by the idea that the kind of knowledge that was assessed in the instrument is closely related to the learning content that is taught in TE. In-service teachers are more likely to have forgotten this learning content, or they might have acquired other learning content in their TE. For instance, a focus on communicative and task-based learning is rather new (González Humanez and Arias 2009; Herazo Rivera 2010), while the in-service participants' average number of years of teaching experience was almost 18 years. The fact that theoretical knowledge on French teaching is constantly evolving calls for more professional support for in-service teachers.

\section{Item 8}

Mister Luc always speaks Dutch during French lessons because he is insecure about his own French ability, and because he thinks the students would not understand him if he would speak French. Give four reasons why it would be good for his students if mister Luc would use French as the main language during French lessons.

Figure 4. Item 8 of the PCK test instrument. 
At the same time, it remains surprising that pre-service teachers did not outperform in-service teachers on declarative knowledge, as the pre-service group is more recently confronted with this kind of learning content. However, the finding that pre-service teachers gave more answers that partially agree with the correction key might indicate that they do have some more declarative knowledge than in-service teachers, but not always succeed in providing comprehensive answers. To understand the effect of experience it is perhaps more fruitful to look at the nature of teachers' answers than only at the number of correct answers.

Regarding the qualitative PCK, differences were found between the two groups. In-service teachers gave more answers showing non-alignment with the correct answers than preservice teachers. Further analyses of the answers showed that especially the items that focused on specific concepts were more difficult for in-service teachers. For instance, in-service teachers were less likely than pre-service teachers to know what OI is. Pre-service teachers performed better on these items, probably because the conceptual knowledge that is necessary to solve these items is more closely aligned to the learning content provided in TE. Previous studies have shown the impact of courses in TE on pre-service teachers' theoretical knowledge (Evens, Elen, and Depaepe 2017; Blömeke et al. 2014). In-service teachers probably did not learn about $\mathrm{OI}$ during their own TE, as $\mathrm{Ol}$ is recently getting more attention in the field of language education (González Humanez and Arias 2009; Herazo Rivera 2010). Our results confirm the statement of Kwakernaak (2009) that educational practice on Ol is lagging behind. If teachers do not know what the concept OI means, chances are high that they will not often purposely provide opportunities for students to practise OI. This is problematic due to the important role that practising OI plays in preparing students for conversations in the real world (Kwakernaak 2009) and because of the link between Ol skills and second/foreign language ability (Naughton 2006). There is a need to provide teachers with ongoing support throughout their careers in order to improve in-service teachers' knowledge on Ol, and to eventually lead to improved practice on Ol (Arzi and White 2007).

Another reason why in-service teachers gave more non-aligning answers than pre-service teachers is that in-service teachers more often referred to their practical knowledge. This finding supports the idea that PCK of in-service teachers is more closely related to craft knowledge (van Driel, Verloop, and de Vos 1998) than to static, declarative knowledge. Many answers cited above illustrate that craft knowledge is not always in accordance with theoretical conceptions of teaching and learning. On the other hand, the finding that the maximum score among the in-service teachers was as high as the maximum score among pre-service teachers, indicates that craft knowledge is not the opposite of theoretical knowledge (van Driel, Verloop, and de Vos 1998; Verloop, Van Driel, and Meijer 2001).

Another finding is that pre-service teachers left more items unanswered. This might indicate a difference in motivation between the groups. The in-service teachers purposely chose to take part in the study, while the students participated in the context of a course that was part of their TE programme. Another reason why pre-service teachers more often gave no answer is that they have less craft knowledge than in-service teachers (van Driel, Verloop, and de Vos 1998). When not knowing the answer on a test item, in-service teachers might have been more inclined to write something they knew based on their practical experiences. Pre-service teachers, on the other hand, might have decided more often to leave an item unanswered because of a lack of this kind of knowledge.

Across items it is remarkable that in-service teachers more often mention their students when formulating answers than pre-service teachers. Throughout their answers in-service 
teachers referred more to students' thinking (see for instance the quotes described above to illustrate that in-service teachers use their practical knowledge when answering questions). This finding is in accordance with previous research showing that pre-service teachers have only poor knowledge of student understanding (Tirosh 2000) and that teaching experience contributes to teachers' knowledge of student understanding (Lee et al. 2007). Experiences with different groups of students throughout their teaching careers might have improved in-service teachers' knowledge of student understanding, and of common mistakes that students are confronted with.

The strength of the current study is that it analysed the impact of teaching experience not only in a quantitative way, but also in a qualitative way, which has led to better understanding of PCK development. However, some factors might limit the generalisability of our conclusions. Firstly, some remarks should be made about the sample. As our study took place in ecologically valid contexts (primary schools and teacher education institutes), we could not control all possible confounds, and as such we cannot make claims about causality. It was very difficult to find in-service teachers willing to participate in the study on a voluntary basis. Consequently, the group of in-service teachers was smaller than the group of preservice teachers. Furthermore, the in-service teachers were not totally randomly selected. Participating teachers might be more motivated to teach French, or have better French language skills than the average primary school teacher, which possibly led to a bias in favour of the in-service teachers. The differences concerning the quality of PCK might have been less compelling when a totally random sample would have been studied. The group of pre-service teachers, on the other hand, was more diverse as all third-year students in both institutes took part in the study. A challenge for future research is to include a diverse sample of in-service teachers, or to study this issue in a more controlled setting, including the matching of participants on background characteristics. Secondly, as mentioned before, the instruments only allowed to capture declarative knowledge. When more situated knowledge would have been studied (e.g. by means of qualitative instruments), other results might have been found (e.g. Clermont, Borko, and Krajcik 1994; Friedrichsen et al. 2009; Park and Oliver 2008). Further research could broaden the results of the present study with findings from a situated perspective. Thirdly, while our PCK instrument had good validity, its internal consistency did not meet the cut-off level of $\alpha=.7$. Our instrument had a lower alpha value than instruments in other domains, for instance König et al. (2016) (English, $\alpha=.67,-.72$ ), Kleickmann et al. (2013) (mathematics, $\alpha=.71,-.77$ ), and Schmelzing et al. (2013) (biology, $\alpha=.78$ ). It is of course hard to compare our instrument to other domains because of the very specific context of our study, that is, French in Flemish primary education. The domain of mathematics, for instance, has a richer general research base on domain-specific learning and teaching, which provides a firmer basis to develop test items (van Driel and Verloop 1998). Furthermore, our instrument was rather short due to time restrictions when collecting data, and Cronbach's alpha increases with test length (Field 2013). Moreover, when instruments do not use continuous scales (like our instrument that uses a binary scale), the chances are higher that alpha coefficients underestimate the real internal consistency of the instrument (McNeish 2017). It is important to keep the lower alpha value in mind when interpreting the results of our study, as it might have biased our findings. Taken together, our instrument is usable but there is room for further optimisation. 
Fourthly, the study followed a cross-sectional design. For future research it would be interesting to longitudinally follow one cohort of teachers from their pre-service TE throughout their careers.

In conclusion, the present study has shown that teaching experience does not contribute to how much declarative French PCK teachers show on our instrument. This finding is in accordance with earlier findings in other domains, such as mathematics. By contrast, the study has shown qualitative differences between pre-service and in-service teachers' PCK. More specifically, in-service teachers have less conceptual knowledge of concepts like OI than pre-service teachers. Meanwhile, in-service teachers more often rely on their knowledge about student understanding than pre-service teachers. The study confirms the idea that declarative knowledge mainly develops during $T E$, while practical knowledge mainly develops as teachers gain more experience. These findings call for more professional development on OI for in-service teachers to improve teaching practice in French lessons. For TE the findings confirm the importance of field experiences, as these have a positive impact on at least some parts of teachers' professional knowledge (such as knowledge about students' understanding). Methodologically, the present study has shown the importance of not only studying total scores on instruments assessing teacher knowledge, but also providing qualitative descriptions of teacher knowledge, as results from both perspectives complement each other.

\section{Disclosure statement}

No potential conflict of interest was reported by the authors.

\section{Notes on contributors}

Marie Evens is a PhD candidate at KU Leuven, Centre for Instructional Psychology and Technology. Her research focuses on teacher professional knowledge in the domain of French as a foreign language, and more specifically on how teacher education and teaching experience impact this kind of knowledge.

Kelly Tielemans is a research assistant at KU Leuven, Centre for Educational Effectiveness and Evaluation. She contributed to this paper in the context of her Master's thesis.

Jan Elen is a full professor at the Faculty of Psychology and Educational Sciences of KU Leuven, teaching courses on educational psychology and technology. As a researcher he is connected to the Centre for Instructional Psychology and Technology. His research focuses on the domains of educational technology and teacher education.

Fien Depaepe is an assistant professor in educational sciences at KU Leuven, Centre for Instructional Psychology and Technology. Her major research interests are at the intersection of mathematics education and teacher education. She is interested in cognitive (e.g. content knowledge, pedagogical content knowledge) and affective factors (e.g. beliefs, attitudes) that influence mathematics teaching and learning. More recently, she is also involved in research on teachers' professional competence in other disciplines, such as French as a foreign language and STEM.

\section{References}

Altman, D. G. 1999. Practical Statistics for Medical Research. New York, NY: Chapman \& Hall/CRC Press. Arzi, H. J., and R. T. White. 2007. “Change in Teachers'Knowledge of Subject Matter: A 17-year Longitudinal

Study." Science Education 92: 221-251. doi:10.1002/sce.20239. 
Evens, M., J. Elen, and F. Depaepe. 2015. “Developing Pedagogical Content Knowledge: Lessons Learned from Intervention Studies." Education Research International : 1-24. doi:10.1155/2015/790417.

Evens, M., J. Elen, and F. Depaepe. 2017. "Effects of Opportunities to Learn in Teacher Education on the Development of Teachers' Professional Knowledge of French as a Foreign Language." Journal of Advances in Education Research 2: 265-279. doi:10.22606/jaer.2017.24007.

Baumert, J., and M. Kunter. 2013. "The COACTIV Model of Teachers' Professional Competence." In Cognitive Activation in the Mathematics Classroom and Professional Competence of Teachers: Results from the COACTIV Project, edited by M. Kunter, J. Baumert, W. Blum, U. Klusmann, S. Krauss and M. Neubrand, 25-48. New York, NY: Springer.

Baumert, J., M. Kunter, W. Blum, M. Brunner, T. Voss, A. Jordan, U. Klusmann, S. Krauss, M. Neubrand, and Y.Tsai. 2010. “Teachers' Mathematical Knowledge, Cognitive Activation in the Classroom, and Student Progress." American Educational Research Journal 47: 133-180. doi:10.3102/0002831209345157.

Bendermacher, N. 2010. "Beyond Alpha: Lower Bounds for the Reliability of Tests." Journal of Modern Applied Statistical Methods 9: 94-102 http://digitalcommons.wayne.edu/jmasm/vol9/iss1/11/.

Blömeke, S., N. Buchholtz, U. Suhl, and G. Kaiser. 2014. “Resolving the Chicken-or-Egg Causality Dilemma: The Longitudinal Interplay of Teacher Knowledge and Teacher Beliefs." Teaching and Teacher Education 37: 30-39. doi:10.1016/j.tate.2013.10.007.

Blömeke, S., U. Suhl, G. Kaiser, and M. Döhrmann. 2012. “Family Background, Entry Selectivity and Opportunities to Learn: What Matters in Primary Teacher Education? An International Comparison of Fifteen Countries." Teaching and Teacher Education 28: 44-55. doi:10.1016/j.tate.2011.08.006.

Bologna Working Group. 2005. A Framework for Qualifications of the European higher Education Area. Accessed February 15, 2017. http://ecahe.eu/w/images/7/76/A_Framework_for_Qualifications_for_ the_European_Higher_Education_Area.pdf

Brunner, M., M. Kunter, S. Krauss, J. Baumert, W. Blum, T. Dubberke, A. Jordan, U. Klusmann, Y. Tsai, and M. Neubrand. 2006. "Welche Zusammenhänge bestehen zwischen dem fachspezifischen Professionswissen von Mathematiklehrkräften und ihrer Ausbildung sowie beruflichen Fortbildung? [How is the Content Specific Professional Knowledge of Mathematics Teachers Related to their Teacher Education and In-service Training?]." Zeitschrift für Erziehungswissenschaft 9: 521-544. doi:10.1007/s11618-006-0166-1.

Clermont, C. P., H. Borko, and J. S. Krajcik. 1994. "Comparative Study of the Pedagogical Content Knowledge of Experienced and Novice Chemical Demonstrators." Journal of Research in Science Teaching 31: 419-441. doi:10.1002/tea.3660310409.

Cochran-Smith, M., and K. M. Zeichner. 2005. Studying Teacher Education: The Report of the AERA Panel on Research and Teacher Education. Mahwah, NJ: Erlbaum.

Connelly, F. M., D. J. Clandinin, and M. F. He. 1997. "Teachers' Personal Practical Knowledge on the Professional Knowledge Landscape." Teaching and Teacher Education 13: 665-674. doi:10.1016/ S0742-051X(97)00014-0.

Council of Europe. n.d. Common European Framework of Reference for Languages: Learning, Teaching, Assessment. Accessed September 21, 2016. http://www.coe.int/t/dg4/linguistic/Source/Framework_ EN.pdf.

Day, T. 2005. "Teachers' Craft Knowledge: A Constant in Times of Change?" Irish Educational Studies 24: 21-30. doi:10.1080/03323310500184343.

Depaepe, F., L. Verschaffel, and G. Kelchtermans. 2013. “Pedagogical Content Knowledge: A Systematic Review of the Way in Which the Concept has Pervaded Mathematics Educational Research." Teaching and Teacher Education 34: 12-25. doi:10.1016/j.tate.2014.12.009.

van Driel, J. H., and N. Verloop. 1998. "'Pedagogical Content Knowledge': een verbindend element in de kennisbasis van docenten ['Pedagogical Content Knowledge': A Unifying Element in the Knowledge Base of Teachers]." Pedagogische Studiën 75: 225-237.

van Driel, J. H., N. Verloop, and W. de Vos. 1998. "Developing Science Teachers' Pedagogical Content Knowledge." Journal of Research in Science Teaching 35: 673-695. doi:10.1002/(SICI)10982736(199808)35:6<673::AID-TEA5>3.0.CO;2-J.

Dunn, T. G., and C. Shriner. 1999. "Deliberate Practice in Teaching: What Teachers do for SelfImprovement." Teaching and Teacher Education 15: 631-651. doi:10.1016/S0742-051X(98)00068-7. 
Eick, C. J., and C. Reed. 2002. "What Makes an Inquiry-Oriented Science Teacher? The Influence of Learning Histories on Student Teacher Role Identity and Practice." Science Education 86: 401-416. doi:10.1002/sce.10020.

Ericsson, K. A., R. T. Krampe, and C. Tesch-Römer. 1993. "The Role of Deliberate Practice in the Acquisition of Expert Performance." Psychological Review 100: 363-406. doi:10.1037//0033-295X.100.3.363.

Field, A. 2013. Discovering Statistics Using IBM SPSS Statistics. London: Sage.

Förtsch, C., S. Werner, L. von Kotzebue, and B. J. Neuhaus. 2016. “Effects of Biology Teachers' Professional Knowledge and Cognitive Activation on Students' Achievement." International Journal of Science Education 38: 2642-2666. doi:10.1080/09500693.2016.1257170.

Friedrichsen, P. J., S. K. Abell, E. M. Pareja, P. L. Brown, D. M. Lankford, and M. J. Volkmann. 2009. “Does Teaching Experience Matter? Examining Biology Teachers' Prior Knowledge for Teaching in an Alternative Certification Program." Journal of Research in Science Teaching 46: 357-383. doi:10.1002/ tea.20283.

Gess-Newsome, J. 2015. "A Model of Teacher Professional Knowledge and Skill including PCK: Results of the Thinking from the PCK Summit." In Re-examining Pedagogical Content Knowledge in Science Education, edited by A. Berry, P. Friedrichsen and J. Loughran, 29-45. New York, NY: Routledge.

González Humanez, L. E., and N. Arias. 2009. "Enhancing Oral Interaction in English as a Foreign Language Through Task-Based Learning Activities." Latin American Journal of Content \& Language Integrated Learning 2: 1-9. doi:10.5294/laclil.2009.2.2.10.

Grossman, P. L. 1990. The Making of a Teacher: Teacher Knowledge and Teacher Education. New York, NY: Teachers College Press.

Haston, W., and A. Leon-Guerrero. 2008. "Sources of Pedagogical Content Knowledge: Reports by Preservice Instrumental Music Teachers." Journal of Music Teacher Education 17: 48-59. doi:10.1177/1057083708317644.

Hattie, J. 2012. Visible Learning for Teachers: Maximizing Impact on Learning. London: Routledge.

Herazo Rivera, J. D. 2010. "Authentic Oral Interaction in the EFL Class: What it Means, What it Does Not." PROFILE Issues in Teachers' Professional Development 12: 47-61 http://www.revistas.unal.edu. co/index.php/profile/article/view/13833.

Hlas, A., and S. Hildebrandt. 2010. "Spanish Liberal Arts and Spanish Education Majors' Writing." L2 Journal 2: 1-22. http://escholarship.org/uc/item/9t09n5x9.

Kaiser, G., S. Blömeke, J. König, A. Busse, M. Döhrmann, and J. Hoth. 2017."Professional Competencies of (prospective) Mathematics Teachers-Cognitive Versus Situated Approaches." Educational Studies in Mathematics 94: 161-182. doi:10.1007/s10649-016-9713-8.

Keller, M., K. Neumann, and H. Fischer. 2017. “The Impact of Physics Teachers' Pedagogical Content Knowledge and Motivation on Students' Achievement and Interest." Journal of Research in Science Teaching 54: 586-614. doi:10.1002/tea.21378.

Kind, V. 2009. "Pedagogical Content Knowledge in Science Education: Perspectives and Potential for Progress." Studies in Science Education 45: 169-204. doi:10.1080/03057260903142285.

Kleickmann, T., D. Richter, M. Kunter, J. Elsner, M. Besser, S. Krauss, and J. Baumert. 2013. "Teachers' Content Knowledge and Pedagogical Content Knowledge: The Role of Structural Differences in Teacher Education." Journal of Teacher Education 64: 90-106. doi:10.1177/0022487112460398.

Krauss, S., J. Baumert, and W. Blum. 2008a. "Secondary Mathematics Teachers' Pedagogical Content Knowledge and Content Knowledge: Validation of the COACTIV Constructs." ZDM Mathematics Education 40: 873-892. doi:10.1007/s11858-008-0141-9.

Kunter, M., U. Klusmann, J. Baumert, D. Richter, T. Voss, and A. Hachfeld. 2013. “Professional Competence of Teachers: Effects on Instructional Quality and Student Development." Journal of Educational Psychology 105: 805-820. doi:10.1037/a0032583.

Kwakernaak, E. 2009. Didactiek van het Vreemdetalenonderwijs [Didactics of Foreign Language Education]. Bussum: Coutinho.

Labaree, D. F. 2000. "On the Nature of Teaching and Teacher Education: Difficult Practices that Look Easy." Journal of Teacher Education 51: 228-233. doi:10.1177/0022487100051003011.

Lee, E., M. N. Brown, J. A. Luft, and G. H. Roehrig. 2007. “Assessing Beginning Secondary Science Teachers' PCK: Pilot Year Results." School Science and Mathematics 107: 52-60. doi:10.1111/j.1949-8594.2007. tb17768.x. 
Lortie, D. C. 1975. Schoolteacher: A Sociological Study. Chicago, IL: University of Chicago Press.

Magnusson, S., J. C. Krajcik, and H. Borko. 1999. "Nature, Sources and Development of Pedagogical Content Knowledge for Science Teaching." In Examining Pedagogical Content Knowledge, edited by J. Gess-Newsome and N. G. Lederman, 95-132. Dordrecht: Kluwer Academic Publishers.

Mahler, D., J. Großschedl, and U. Harms. 2017. “Using Doubly Latent Multilevel Analysis to Elucidate Relationships Between Science Teachers' Professional Knowledge and Students' Performance." International Journal of Science Education 39: 213-237. doi:10.1080/09500693.2016.1276641.

McNeish, D. 2017. Thanks Coefficient Alpha, We'll Take it From Here. Psychological Methods. Advance online publication. doi:10.1037/met0000144.

Naughton, D. 2006. "Cooperative Strategy Training and Oral Interaction: Enhancing Small Group Communication in the Language Classroom." The Modern Language Journal 90: 169-184. doi:10.1111/ j.1540-4781.2006.00391.x.

Park, S., and J. S. Oliver. 2008. "Revisiting the Conceptualisation of Pedagogical Content Knowledge (PCK): PCK as a Conceptual Tool to Understand Teachers as Professionals." Research in Science Education 38: 261-284. doi:10.1007/s11165-007-9049-6.

Qian, H., and P. Youngs. 2016. "The Effect of Teacher Education Programs on Future Elementary Mathematics Teachers' Knowledge: A Five-Country Analysis Using TEDS-M Data." Journal of Mathematics Teacher Education 19: 371-396. doi:10.1007/s10857-014-9297-0.

Schleicher, A. 2016. Teaching Excellence Through Professional Learning and Policy Reform. Paris: OECD.

Schmelzing, S., J. H. van Driel, M. Jüttner, S. Brandenbusch, A. Sandmann, and B. J. Neuhaus. 2013. "Development, Evaluation, and Validation of a Paper-and-Pencil Test for Measuring Two Components of Biology Teachers' Pedagogical Content Knowledge Concerning the "Cardiovascular System"'." International Journal of Science and Mathematics Education 11: 1369-1390. doi:10.1007/s10763012-9384-6.

Schön, D. A. 1983. The Reflective Practitioner: How Professionals Think in Action. New York: Basic Books.

Sercu, L., C. Vyncke, and E. Peters. 2003. Testen en Evalueren in het Vreemdetalenonderwijs [Assessment and Evaluation in Foreign Language Education]. Mechelen: Plantyn.

Shulman, L. S. 1986. "Those Who Understand: Knowledge Growth in Teaching." Educational Researcher 15: 4-14. doi:10.3102/0013189X015002004.

Shulman, L. S. 1987. "Knowledge and Teaching: Foundations of the New Reform." Harvard Educational Review 57: 1-23. doi:10.17763/haer.57.1.j463w79r56455411.

Sijtsma, K. 2009. "On the Use, the Misuse, and the Very Limited Usefulness of Cronbach's Alpha." Psychometrika 74: 107-120. doi:10.1007/s11336-008-9101-0.

Strauss, A., and J. Corbin. 1998. Basics of Qualitative Research. Techniques and Procedures of Developing Grounded Theory. 2nd ed. London: Sage Publications.

Theissen, S., P. Hiligsmann, L. Rasier, and C. Klein. 2015. Nederlands-Frans in contrast, 2000 lexicologische valstrikken in het Frans [Dutch-French in Contrast, 2000 Lexicological Pitfalls in French]. Leuven: Acco.

Tirosh, D. 2000. “Enhancing Prospective Teachers'Knowledge of Children's Misconceptions: The Case of Division of Fractions." Journal for Research in Mathematics Education 31: 5-25. doi:10.2307/749817. Verloop, N., J. H. Van Driel, and P. Meijer. 2001. "Teacher Knowledge and the Knowledge Base of Teaching." International Journal of Educational Research 35: 441-461. doi:10.1016/S0883-0355(02)00003-4. 